\title{
The Effects of Nano-Crystal Distribution and Structure on the Transport in Vanadium Oxide Thin Films
}

\author{
B.D. Gauntt and E.C. Dickey \\ Department of Materials Science and Engineering, Pennsylvania State University, \\ University Park, PA 16802
}

Vanadium oxide thin films are used as the active layer in microbolometers - devices used in infrared imaging cameras which convert incident IR into heat, thereby reducing the resistance of the vanadium oxide layer. The main properties of interest are the room temperature resistivity, which is limited by the underlying readout circuitry, and the thermal coefficient of resistance (TCR), which determines the responsivity of the device [1]. Previous results [2] have shown that FCC vanadium monoxide $\left(\mathrm{VO}_{\mathrm{x}}\right)$ is present in films with resistivity and TCR in the range of device-quality material. To further investigate the effects of microstructure on resistivity and TCR, a series of thin films was deposited using reactive pulsed direct-current sputtering of a vanadium metal target in atmospheric conditions chosen to vary the size and distribution of the $\mathrm{FCC} \mathrm{VO}_{\mathrm{x}}$ phase.

The resulting films were analyzed by cross-sectional transmission electron microscopy (TEM). The left half of Figure 1 shows centered dark-field images of a subset of the series with resistivity in the useful range $(0.1$ to $10 \Omega \mathrm{cm})$. Three of the films shown were made at a total pressure of $2.5 \mathrm{mT}$ Torr with relative $\mathrm{O}_{2}$ flow rates of $7.5 \%(\mathrm{a}), 10 \%$ (b) and $12.5 \%$ (c) of the total gas flow $\left(\mathrm{Ar}+\mathrm{O}_{2}\right)$. The fourth film shown (d) was made at a total pressure of $5 \mathrm{mT}$ Torr with a relative $\mathrm{O}_{2}$ flow rate of $5 \%$. The dark-field images show a gradual decrease in the $\mathrm{VO}_{\mathrm{x}}$ grain size upon increase of the relative $\mathrm{O}_{2}$ flow rate. The same trend can be seen in the radially averaged selected area diffraction patterns shown in the right side of Figure 1, where the peaks attributed to the FCC phase broaden with increasing $\mathrm{O}_{2}$ flow rate. Also present in the diffraction patterns is a broad scattering feature located between 3 to $4 \mathrm{~nm}^{-1}$. This feature was also found in films deemed completely amorphous, and likely represents short range order present as either extensive grain boundary material (which increases in volume fraction with decreasing grain size) or as an amorphous "matrix" surrounding the nanocrystalline phase. Increased oxygen in the sputtering atmosphere caused film resistivity to increase throughout the series. Decreased grain size and increased intensity in the diffuse scattering at $3 \mathrm{~nm}^{-1}$ correlates with increased TCR, suggesting the importance of disorder in high $\mathrm{TCR}_{\mathrm{VO}}$ films. The disordered component appears to be critical in attaining the desired TCR at a given resistivity. An increase in the amorphous/disordered component, which has a much greater resistivity than the FCC phase, causes an overall increase in both the resistivity and TCR, as seen in Figure 3 (left) which shows TCR as a function of room temperature resistivity.

Figure 3 (right) shows SADPs from the 5 mTorr $5 \% \mathrm{O}_{2}$ sample (d) and the 2.5 mTorr $12.5 \% \mathrm{O}_{2}$ sample (c), the later showing evidence of nano-twinned FCC $\mathrm{VO}_{\mathrm{x}}$ [3]. Evidence of the nano-twins is important because twinned grains have been found in commercial ion beam deposited material but have been elusive in most pulsed DC sputtered films. Both films (c) and (d) have the same stoichiometry within the uncertainty of the Rutherford backscattering spectroscopy measurement, and the film exhibiting nano-twinned grains (c) has a considerably higher TCR than film (d), which exhibits similar grain size and disorder, suggesting nano-twinning is also an important microstructural feature in high $\mathrm{TCR} \mathrm{VO}_{\mathrm{x}}$ thin films for use in microbolometers. 
References

[1] P.W. Kruse, Uncooled thermal imaging: Arrays, systems, and applications, SPIE Press, Bellingham, 2002.

[2] B. D. Gauntt et al., J. Mat. Res. 24 (2009) 1590.

[3] J. Li et al., Microsc. Microanal. 15 (Suppl. 2) (2009) 1004CD.
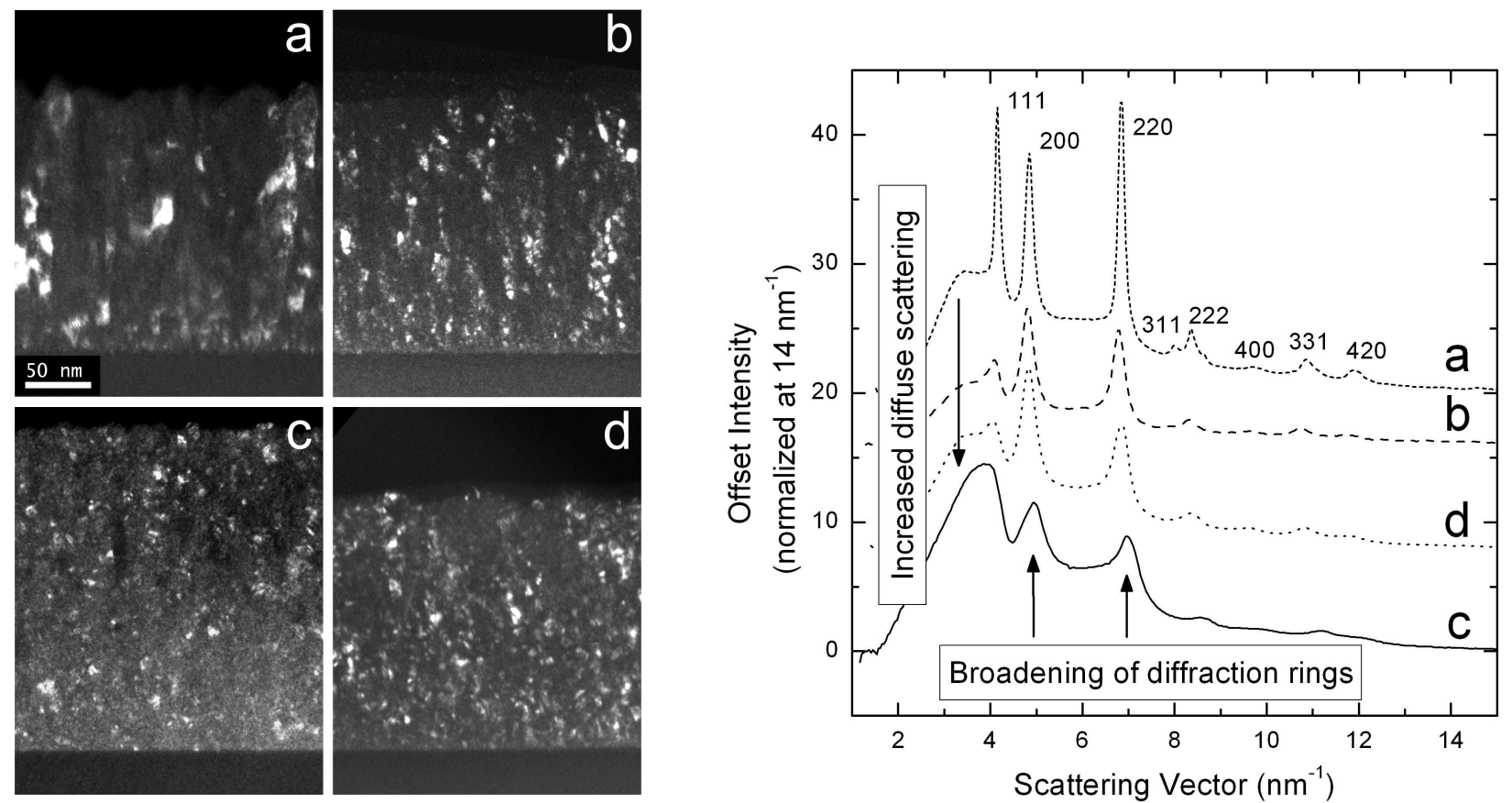

FIG. 1. (left) Dark field cross sectional images of the $\mathrm{VO}_{\mathrm{x}}$ films in this study using the (200) diffraction ring from the $\mathrm{FCC} \mathrm{VO}_{\mathrm{x}}$ phase. (right) Radially integrated selected area diffraction patterns from the films shown to the left. With an increase in the amount of oxygen, films in (a), (b), and (c) show decreasing $\mathrm{FCC} \mathrm{VO}_{\mathrm{x}}$ grain size. The film shown in (d) was processed under very different conditions but shows a microstructure intermediate to (b) and (c).
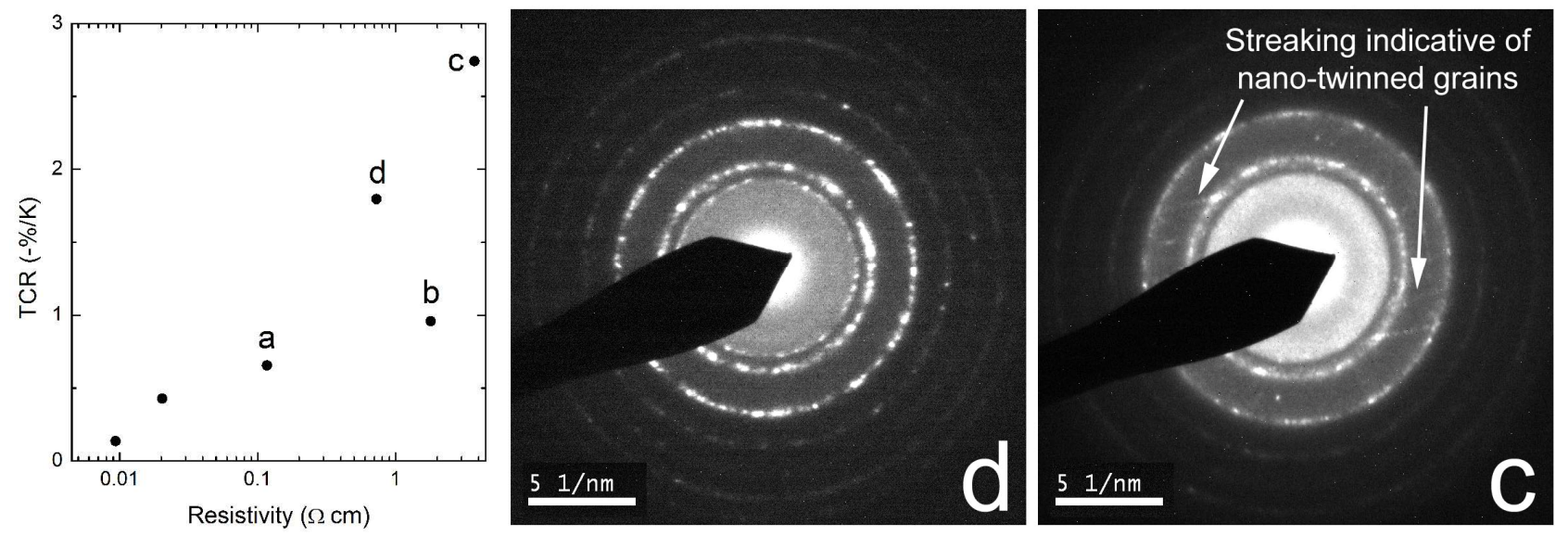

FIG. 2. (left) TCR as a function of room temperature resistivity for films containing $\mathrm{FCC} \mathrm{VO}_{\mathrm{x}}$. (right) SADP from (d) a film containing nano-crystalline VOx and (c) a film containing twinned nano-crystalline $\mathrm{VO}_{\mathrm{x}}$. The streaking, which runs tangential to a "defect ring" just inside the (111) indicates the presence of nano-twinned grains [3]. 